\title{
The Effects of Improved Auditory Feedback on the Verbalizations of an Autistic Child
}

\author{
Donald E. P. Smith, Mary Olson, \\ Frances Barger, and James V. McConnell \\ The University of Michigan, Ann Arbor, and \\ Ingham Developmental Center, Mason, Michigan
}

Failure to use expressive language is a defining characteristic of juvenile autism (Ricks \& Wing, 1975). Indeed, the fact that some $90 \%$ of autistic children end up in institutions seems directly caused by two languagerelated problems-the child's inability to communicate with others, and the child's failure to learn to use "self-talk" as a means of establishing selfcontrol over his thoughts and behaviors. By use of a device called the Phonic Ear, which allows the autistic child to selectively screen out auditory inputs the child does not wish to hear, we sought to increase spontaneous communication in two autistic children.

The most popular types of therapy for autistic children-the use of behavior modification techniques (Lovaas, 1977), teaching the child to use sign language, and intonation therapy-have produced only limited communication in some children. These therapies probably fail because they put the child under increased environmental stress in order to "break through the child's resistances," or because they seldom motivate the child to learn more appropriate behaviors. There is a growing body of evidence, however, that suggests that the most appropriate therapy for autistic children may involve a decrease in stress rather than an increase (Schechter, 1969).

That stress can cause autisticlike symptoms has been documented by Goldfarb and Braunstein (1968). When these investigators subjected schizophrenic children to a delay in auditory feedback of .16 seconds, the children displayed such autisticlike behaviors as screaming, covering the ears, and attacking the equipment. Furthermore, as Hutt, Hutt, Lee, and Ounsted (1964) have shown, the reduction in stress that accompanies sleep is accompanied by normal EEG patterns in sleeping autistic children. 
Taking our cue from these studies, let us assume that autistic children suffer from a type of "input overload" (Miller, 1978) caused by an inability to mask out ambient environmental sounds. In order to reduce the stress associated with this overload condition, these children would tend to block out all auditory stimuli, including the sounds of their own voices, and thus would often be diagnosed as suffering from pseudo- or psychogenic deafness. It would be their failure to make use of auditory feedback involving their own vocalizations, then, that would prevent them from learning to communicate with others and from establishing the internal speech (self-talk) necessary for behavioral self-control.

An essential step in normal language learning is the auditory processing of the child's own utterances, such as that which occurs during babbling and self-talk (Jacobson, 1960). But normal babbling tends not to occur in autistic children (Ricks \& Wing, 1975), and thus they usually fail to learn that language can have instrumental value in controlling their own actions and those of other individuals. We believe that this failure to babble may be associated with the child's inability to block out background noise. Indeed, we suspect that the child's utterances are so distorted in his own ears that he fails to recognize them as being self-generated.

Thus, for the autistic child, expressive language may not be rewarding; rather, it may be punishing (because it increases auditory overload) or nonconsequential. And language behaviors-like all others-tend not to recur unless they are rewarding to the speaker.

\section{METHOD}

In both experiments reported below, we made use of a prosthetic device called the Phonic Ear (H. C. Electronics), which allows the user to control both the direction and the volume of auditory inputs while blocking out environmental sounds the person doesn't wish to hear. The Phonic Ear consists of earphones with a built-in FM receiver. A microphone is suspended near the child's mouth and broadcasts sounds both to the earphones and to a separate FM receiver/tape recorder.

\section{Subject 1}

Our first subject was a healthy 9-year-old black autistic child who was diagnosed as autistic at age 2 . Usually mute (prior to our intervention), he would from time to time repeat a word such as a color name when directed to do so by the teacher, but he seldom spoke spontaneously. When faced with a task at school, he would typically ignore the task and sit with his hands placed at either side of his head, his index fingers pushing his ears 
closed as though to reduce sound. The boy's scores on the Psychoeducational Profile (Schopler \& Reichler, 1976), which had been administered when he was 7.5 years old, ranged from 2 years (verbal and cognitive) to 5 years (perceptual).

\section{Procedure}

We began our intervention by measuring the number of spontaneous utterances emitted by the boy during three daily half-hour periods for a period of 3 successive weeks. We defined spontaneous utterances as sentences, phrases, words, syllables, or phonemes emitted without prompting. Murmurings and unintelligible sounds were not tallied. The boy gave no spontaneous utterances at all during this first baseline period (Figure 1).

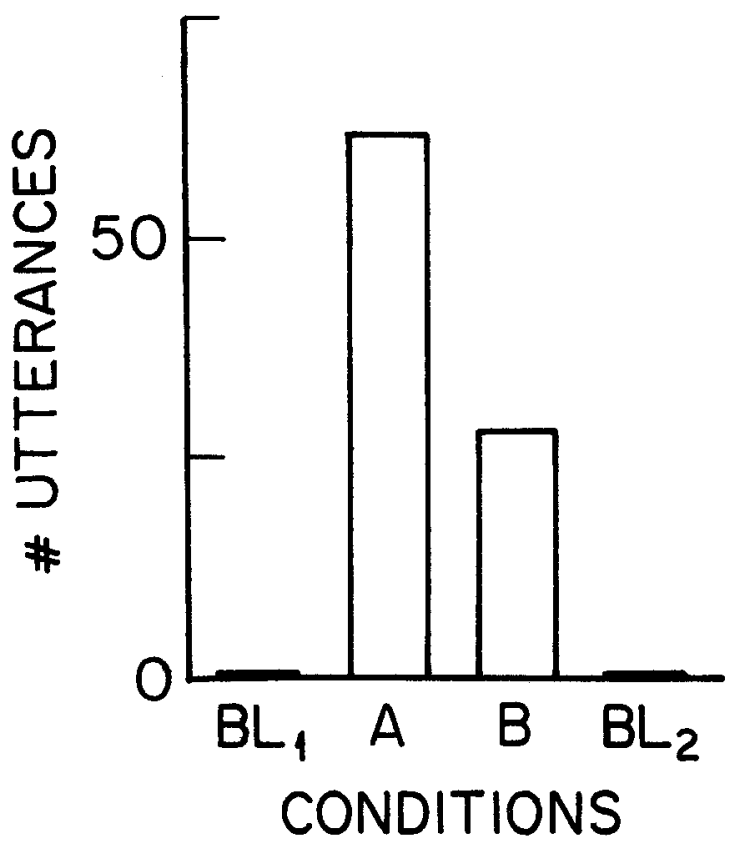

Fig. 1. Frequency of spontaneous utterances in 30-minute periods by an autistic boy (C.A. 9) during initial baseline period (BL $\mathrm{B}_{1}$ ), while wearing Phonic Ear (Condition $A$ ), immediately following (Condition $\mathrm{B})$, and at follow-up $\left(\mathrm{BL}_{2}\right)$. Number of treatments = 13.Differences as determined by pairwise $t$ tests: $\mathrm{BL}_{1}$-Condition A $(p<.01)$; Condition A-Condition B $(p<.05)$. 
We then placed the Phonic Ear on the boy for 30 minutes daily for 26 school days. We measured the boy's spontaneous utterances for 13 of these days both while he wore the device (Condition A) and for the half-hour immediately following (Condition B). During both conditions, the boy participated in various school activities and was able to communicate with at least two adults and three children. School activities included independent work on perceptual activities (puzzles, games) and group training on language and social skills.

\section{RESULTS}

The boy's spontaneous utterances increased significantly while he wore the Phonic Ear (Figure 1, Condition A). This increase tapered off somewhat after the device was removed each day (Condition B). Several weeks after intervention ceased, the boy's spontaneous utterances had returned to almost zero (baseline period 2).

In addition to the quantitative data displayed in Figure 1, we noted the following changes in the boy's behaviors:

1. Routine retesting of the child using the Psychoeducational Profile following intervention revealed an increase of a full year in cognitive and verbal performance (raw score change from 4 to 11).

2. On day 2 of the intervention, the boy attempted to say his teacher's name on several occasions without success (he said "Duph" rather than "Debbie"). On day 3, however, he entered the room, said, "Hi, Debbie," walked to his chair, said, "Sit in chair," and did so. We interpret his attempts to say his teacher's name as self-shaping of language and the directive "Sit in chair" as self-talk, which can lead to self-control.

3. From day 2 onward, the boy strongly resisted his teacher's attempts to remove the Phonic Ear after 30 minutes of use (Condition A). Therefore, we allowed him to remove the device at will, but we tallied his utterances only during the first half hour of use and the half hour immediately after he took off the earphones.

4. By day 3, his prior ear-blocking behaviors disappeared. Several days after the last treatment session, however, these behaviors began recurring.

5. On days when the boy spoke frequently while wearing the Phonic Ear, he seemed to be listening to himself. On days when he spoke less frequently, he appeared to be listening to others and to high-intensity sounds in the environment. On high-speech days, he tended to point the microphone toward his own mouth. On low-speech days, he engaged in such acts as rushing to the lavatory to hold the microphone over a flushing 
toilet or pointed the microphone at another child's mouth while that child was screaming.

6. On day 3, the boy's mother called to report that he was talking spontaneously at home. The mother was, prior to this time, unaware of our intervention.

\section{Subject 2}

We next tested the Phonic Ear with a 14-year-old white male who had been diagnosed as autistic at age 4 . He too emitted significantly more spontaneous utterances when wearing the Phonic Ear than prior or subsequent to intervention. In 5 days of treatment (150 minutes wearing the device), he produced more than 1,000 utterances, all single syllables. And he too had days during which he listened to himself (and spoke more frequently), and days during which he listened to others (and spoke less frequently).

\section{DISCUSSION}

The apparent failure of both subjects to maintain increased levels of verbalization without continued use of the Phonic Ear can be explained in a variety of ways. It may be that our findings were due primarily to a novelty effect. A more likely explanation is that, during the short period each boy wore the device, he did not learn sufficient cognitive skills to allow him to gate out competing auditory stimuli on his own, without the sort of electronic assistance provided by the Phonic Ear. This latter explanation is congruent with findings reported by Pavlidis (cited in Cohen, 1980), who reports that children with severe reading impairment (dyslexia) are unable to track visually a series of lights activated sequentially. We assume that dyslexic children may suffer from an inability to gate out visual stimuli that compete with reading just as autistic children apparently cannot block out auditory stimuli that compete with hearing their own voices.

\section{CONCLUSIONS}

Allowing autistic children to control the volume and direction of their auditory inputs apparently affects their language behavior. Further studies are needed, however, to determine the extent that use of devices such as the Phonic Ear will be of value in increasing vocalizations in these children. 


\section{REFERENCES}

Cohen, D. British society takes stand on Burt; Tackles practical problems. APA Monitor, 1980, $11,1,9$.

Goldfarb, W., \& Braunstein, P. Reactions to delayed auditory feedback among a group of schizophrenic children. In P. H. Hoch \& J. Zubin (Eds.), Psychopathology of communication. New York: Grune and Stratton, 1958. Pp. 49-63.

Hutt, C., Hutt, S. J.,Lee, D., \& Ounsted, C. Arousal and childhood autism. Nature, 1964, 204, 908-909.

Jacobson, R. Concluding statement: Linguistics and poetics. In T. A. Sebeok (Ed.), Style in language. Cambridge: M.I.T. Press, 1960. Pp. 350-377.

Lovaas, $\mathrm{O}$. I. The autistic child: Language development through behavior modification. New York: Irvington, 1977.

Miller, J. G. Living systems. New York: McGraw-Hill, 1978.

Ricks, D. M., \& Wing, L. Language, communication, and the use of symbols in normal and autistic children. Journal of Autism and Childhood Schizophrenia, 1975, 5, 191-221.

Schechter, M. D. Sensory isolation therapy of autistic children: A preliminary report. Journal of Pediatrics, $1969,74$.

Schopler, E., \& Reichler, R. J. Psychoeducational profile. Individualized assessment and treatment for autistic and developmentally delayed children (Vol. I). Baltimore: University Park Press, 1979. 